\title{
National Public Health Institute Legal Framework: A Tool to Build Public Health Capacity
}

Emily L. Rosenfeld, Sue Binder, C. Adam Brush, Ellen A. Spotts Whitney, Dennis Jarvis, Katherine Seib, André R. Verani, Michael A. Flores, and Akshara Narayan Menon

As countries face public health emergencies, building public health capacity to prevent, detect, and respond to threats is a priority. In recent years, national public health institutes (NPHIs) have emerged to play a critical role in strengthening public health systems and to accelerate and achieve implementation of the International Health Regulations (IHR 2005). NPHIs are science-based government institutions that provide national leadership and expertise for the country's efforts to protect and improve health. Providing a Legal Framework for a National Public Health Institute is a recently released Africa CDC publication intended to support NPHI development throughout Africa. Here we present a legal mapping analysis of sampled legal domains for 5 countries, using the "Menu of Considerations for an NPHI Legal Framework." The analysis delineates the types of legal authorities countries may use to establish or enhance NPHIs and demonstrates how legal mapping can be used to review legal instruments for NPHIs. It also demonstrates variability among legal approaches countries take to establish and enable public health functions for NPHIs. This article examines how the legal framework and menu of considerations can help countries understand the nuances around creating and implementing the laws that will govern their organizations and how countries can better engage stakeholders to identify or address potential areas for opportunity where law may be used as a tool to strengthen public health infrastructure.

Keywords: Public health law, National public health institutes, International Health Regulations, Legal framework

W ITH COUNTRIEs increasingly facing disease threats that transcend borders, 196 countries have agreed to implement the International Health Regulations (IHR, 2005). ${ }^{1}$ Additionally, in 2014 the United States and several other countries initiated the Global Health Security Agenda
(GHSA) to spur progress toward full IHR implementation. ${ }^{2}$ The Joint External Evaluation (JEE) tool was developed and adopted by the World Health Organization (WHO) to help countries identify gaps and measure progress toward meeting full IHR implementation. ${ }^{3}$ Law and

Emily L. Rosenfeld, JD, MPH, is a Public Health Analyst, and C. Adam Brush, MSW, MPH, is Team Lead; both in the Office of the Associate Director for Policy; Dennis Jarvis, MPH, is a Public Health Advisor, National Public Health Institute Program, Division of Global Health Protection, and André R. Verani, JD, MPH, is a Policy Analyst, Division of Global HIV and TB; all are in the Center for Global Health, US Centers for Disease Control and Prevention, Atlanta, GA. Sue Binder, MD, is a Senior Advisor for Public Health Practice; Ellen A. Spotts Whitney, MPH, is Director, US Office; Katherine Seib, MSPH, is Director of Programs; and Michael A. Flores, MPH, is a Graduate Research Assistant; all at IANPHI, Global Health Institute, Emory University, Atlanta, GA. Akshara Narayan Menon, JD, MPH, is a Public Health Analyst (Cherokee Nation Assurance Contractor), Public Health Law Program, US Centers for Disease Control and Prevention, Atlanta, GA. The findings and conclusions in this report are those of the authors and do not necessarily represent the official position of the Centers for Disease Control and Prevention. 
policy issues are included throughout the JEE, underscoring the impact that law and policy can have on improving global health security and public health capacity. ${ }^{3}$ As countries seek to improve capacities measured by the JEE, strengthening legal authorities can be used in multiple ways to enhance compliance with IHR obligations. ${ }^{4}$ In particular, the national, policy, and financing capacity section of the JEE specifies the role legal frameworks can play in enabling IHR implementation. ${ }^{5}$ While none of the 19 technical areas in the JEE tool expressly assesses the functions of national public health institutes (NPHIs), the institutes can provide a centralized platform for implementation across technical areas.

National public health institutes have emerged as playing a critical role in coordinating, developing, and strengthening public health capacities; helping countries achieve IHR implementation; and improving population health. ${ }^{6,7}$ As science-based government organizations, ${ }^{8}$ NPHIs often serve as the focal points for efforts to protect, strengthen, and improve health, catalyzing responses to key public health challenges. ${ }^{9,10}$ Typical NPHI functions with direct implications for health security include public health laboratory and surveillance systems, emergency preparedness and response, public health workforce development, and research in public health. In addition, NPHIs often lead in developing One Health* approaches to surveillance, disease prevention, and emergency response and can also bridge the gap between clinical and public health systems. ${ }^{2,10,11}$

In 2017, the African Union created the Africa Centres for Disease Control and Prevention (Africa CDC) to support public health throughout the continent. Africa CDC has prioritized the development of strong NPHIs in all African countries and has developed guidance for countries. This includes Providing a Legal Framework for a National Public Health Institute, ${ }^{12}$ a guidance document that includes the "Menu of Considerations for an NPHI Legal Framework." This framework was developed in 2019 as a joint effort of the International Association of National Public Health Institutes (IANPHI), the US Centers for Disease Control and Prevention (US CDC), Public Health England, and African NPHI directors from Ethiopia, Guinea Bissau, Liberia, Mozambique, Nigeria, and South Africa. ${ }^{9,12}$ These documents underscore that development of a legal instrument that clearly defines what an NPHI will do and how it will operate within the government's structure is an important step in clarifying the NPHI's mission, governance, reporting structure, leadership, and finance and will contribute to success. ${ }^{12}$

The legal process used to establish or restructure an NPHI varies greatly from country to country and therefore requires deliberate steps to ensure sustainability of an NPHI in the health system. Thus, the NPHI Legal Framework provides information and perspectives for countries seeking to enable their NPHIs with legal authorities. Based on in-

*One Health recognizes that the health of people is connected to the health of animals and the environment. depth consultations with stakeholders and a thorough review and analysis of existing public health laws related to NPHIs, NPHI strategic guidance documents, and legal literature, ${ }^{12}$ the NPHI Legal Framework includes 7 core legal domains:

I. Establishment: Outlines legal character and organizational identity of the NPHI

II. Functions: Specifies the work to be carried out by an NPHI

III. Leadership: Characterizes the leadership structure of an NPHI

IV. Oversight and Advisory Boards: Relates to establishment, function, operation, and membership

V. Accountability and Reporting: Provides a legal basis for reporting and oversight within a government's structure

VI. Financial Resources and Their Use: Authorizes funds and certain aspects related to their use

VII. Effective Date: States when the law becomes effective and any necessary preconditions

To identify these legal domains, global public health literature was analyzed and technical guidance and input from subject matter experts were sought to further refine the domains. Each domain contains legal attributes, with 140 legal attributes across all domains. The domains and attributes together provide a framework to assist in characterizing NPHI legal authorities - both the existing legal landscape and opportunities to use law as a tool to strengthen public health infrastructure, including further supporting IHR compliance. ${ }^{5}$ In the analysis below, we provide an example of how using a legal framework can assist with systematically mapping a country's laws to identify potential gaps and provide opportunities where law may be used as a tool to strengthen public health infrastructure.

\section{Methods}

Global public health law $^{\dagger}$ and policy experts from US CDC, assisted by IANPHI, conducted an initial scan of

†Public health law is the study of the legal powers and duties of the state, in collaboration with its partners, to assure the conditions for people to be healthy, and the limitations on the power of the state to constrain the autonomy, privacy, liberty, and proprietary or other legally protected interests of individuals for the common good. In order to utilize public health law as a tool to strengthen public health, systematically mapping a country's laws can assist in identifying potential gaps and opportunities to align legal authority to act with other national action plans, guidelines, and IHR requirements. Frameworks that define legal characteristics and attributes can provide a basis for review, as such frameworks align with public health activities and provide a menu of considerations, including legal authorities and functional characteristics. ${ }^{13}$ 
Table 1. Legal Coding for Domain I: The Legal Instrument Establishes the NPHI

\begin{tabular}{|c|c|c|c|c|c|}
\hline Domain I: The legal instrument establishes the NPHI & Ethiopia & Guinea-Bissau & Liberia & Mozambique & Nigeria \\
\hline \multicolumn{6}{|l|}{ The legal instrument ... } \\
\hline 1.1 ... establishes an NPHI. & $\bullet$ & $\bullet$ & $\bullet$ & $\bullet$ & $\bullet$ \\
\hline $1.2 \ldots$ establishes the NPHI as a parastatal entity. & $\bullet$ & $\bullet$ & $\bullet$ & $\bullet$ & $\bullet$ \\
\hline $1.2 .1 \ldots$ articulates a reporting structure. & & & $\bullet$ & $\bullet$ & \\
\hline 1.2.2 ... describes functions and operations. & $\bullet$ & $\bullet$ & $\bullet$ & $\bullet$ & $\bullet$ \\
\hline 1.2.2.1 ... describes the scope of duties. & $\bullet$ & $\bullet$ & $\bullet$ & $\bullet$ & $\bullet$ \\
\hline 1.2.2.2 $\ldots$ includes limitations on authorities. & & & & $\bullet$ & \\
\hline \multicolumn{6}{|l|}{$\begin{array}{l}1.3 \ldots \text { incorporates or establishes the NPHI within } \\
\text { the existing ministry of health organization. }\end{array}$} \\
\hline \multicolumn{6}{|l|}{ 1.3.1 ... articulates a reporting structure. } \\
\hline \multicolumn{6}{|l|}{ 1.3.2 $\ldots$ describes functions and operations. } \\
\hline \multicolumn{6}{|l|}{ 1.3.2.1 $\ldots$ describes the scope of duties. } \\
\hline 1.3.2.2 $\ldots$ includes limitations on authorities. & & & & & \\
\hline
\end{tabular}

national NPHI laws* enacted through April 15, 2019. Researchers selected for analysis NPHI legal instruments from 5 African countries-Ethiopia, ${ }^{14,15}$ Guinea-Bissau, ${ }^{16} \mathrm{Li}$ beria, ${ }^{17}$ Mozambique, ${ }^{18,19}$ and Nigeria ${ }^{20,21}$-representative of different geographic regions and legal systems from the African continent. Copies of laws were obtained from IANPHI's online database, including translated copies of laws from Guinea-Bissau and Mozambique. Only national laws were analyzed using the NPHI Legal Framework; subnational laws, international laws, policies, national strategic plans, and other guidance documents were not included in the scope of the analyses. Researchers used legal epidemiologic methodologies ${ }^{5,22}$ to systematically review and code these national laws for the presence or absence of all legal domains and attributes included in the NPHI Legal Framework. Each of 3 reviewers independently coded laws for up to 2 countries, and then coders collectively reviewed and validated codes to ensure interrater agreement was achieved. Quality control measures were implemented to ensure coding integrity.

\section{ANALYSIS}

While an analysis of all domains and attributes was completed, the discussion presented here focuses on domains I, II, III, IV, and V, which relate to the legal character of the NPHI, functions of the NPHI, leadership structure, accountability, and reporting. Additional details for all domains and attributes are included in the appendix (see supplemental material at https://www.liebertpub.com/doi/ suppl/10.1089/hs.2019.0093/).

\footnotetext{
National laws include primary enabling authorities, such as statutes and acts, and also secondary authorities with force of law, including administrative regulations, rules, decrees, and orders.
}

\section{Legal Character of the NPHI}

Domain I, "The legal instrument establishes the NPHI," includes attributes related to both the creation and legal identity of the NPHI (Table 1). All countries included in this review used legal authority to establish the NPHI. For example, in Mozambique, the NPHI is "endowed with legal personality, with administrative and technical-scientific autonomy." 18,19 In Ethiopia, the NPHI is an "autonomous federal government office" that has its "own legal personality." ${ }^{14}$ Liberia's NPHI is an "autonomous agency of the government," 17 and Guinea-Bissau's has its own "juridical personality, endowed with technical, administrative, financial, and patrimonial autonomy." 16 Lastly, Nigeria's NPHI is enabled as "a body corporate with perpetual succession."20

All 5 NPHIs are authorized as parastatal entities, although the definition of parastatal and the implications for oversight and use of ministry systems (eg, for hiring and finances) vary across countries. The review showed significant diversity in autonomy and, in particular, reporting to and oversight by ministries of health. Laws for Mozambique, Ethiopia, Guinea-Bissau, Liberia, and Nigeria codify relationships between the NPHIs and ministries of health or other government entities. For example, in Nigeria, the "Centre shall submit annual costed work plans relating to its functions to the Minister for approval." 20 Liberia's law requires "proper coordination" and "sectoral reporting accountability to the Ministry of Health." 17 Mozambique's Ministry of Health has "guardianship" of the NPHI, which includes power to inspect the structure of the NPHI and authorize and approve annual reports, programs, bodies, and activity plans. ${ }^{18}$

Legal authorities for all 5 countries articulate public health functions and scope of duties for the NPHI. For example, Ethiopia's law provides a list of 21 specific duties, 
with particular emphasis on the NPHI's role in conducting public health research, ${ }^{14}$ while Liberia's law includes broader categories, such as development and sustainability of the public health workforce, surveillance and laboratory capacity, environmental and occupational health structures, and coordinated public health and medical research. ${ }^{15}$ Likewise, while Mozambique's law includes core "attributions" and "competencies" 16 to authorize functions and operations for the NPHI, an organic statute subsequent to the law specifies a regulatory process to clarify the public health functions of the NPHI. ${ }^{17}$

\section{Public Health Functions of the NPHI}

Domain II includes specific functions, including public health functions that may be legally authorized for NPHIs (Table 2). All 5 countries reviewed include authorization for the following functions: (1) administrative, (2) laboratory and (3) surveillance systems, (4) disease prevention and promotion, (5) workforce development, and (6) health research and development. Ethiopia, Liberia, and Nigeria also authorize public health emergency response.

In Ethiopia, the NPHI is directed to "design strategies, issue guidelines, develop preparedness and response plans, build capacity, establish and implement coordination and collaboration frameworks, conduct public health vulnerability assessment and risk analysis, and provide public health support to prevent and mitigate public health emergencies." 14 This also includes authorization to conduct "... on site investigation when deemed necessary, verify outbreaks, issue alerts, provide warning and disseminate information to the concerned organizations, mobilize or cause the mobilization of resources, and support the response activities carried out. ..."14 Ethiopia also requires that there be a focal point for communication to "implement international health regulations on grave public health emergencies having implications of international crisis." 14

Nigeria has expressly included language dedicating their NPHI as the IHR focal point. ${ }^{20}$ Moreover, in Liberia, in addition to supporting "the health response and provid[ing] recommendations to government on control measures for disease outbreaks and mitigating health risks and hazards," 17 the NPHI is also authorized to "recommend the declaration of public health emergency and disease outbreaks based on available public health data." 17

\section{Leadership of the NPHI}

Domain III describes laws related to leadership roles in the NPHI (Table 3). All 5 countries authorize an NPHI director and include legal requirements for appointment, removal, and tenure. For instance, in Mozambique, the director is "appointed by the Prime Minister, on the proposal of the Minister overseeing the area of Health."18,19 In Liberia the "President shall, upon the recommendations of the Board of Directors, appoint the Director General." 17
Laws in Ethiopia, Nigeria, Liberia, and Guinea-Bissau include qualifications or other competencies for the NPHI director. For example, in Guinea-Bissau, the NPHI director must be selected "among doctorates in medicine or related fields." 16 Nigeria goes further, mandating that the director "shall be a health professional with at least 15 years post graduate qualification experience in medicine or public health." 20 Only Ethiopia and Mozambique include language describing limitations on authority for the NPHI director. For example, in Mozambique, the director general shall "define the general direction of management and direct the activities of the Instituto Nacional de Saude (INS), with the vision of realizing its attributions, reporting to the Minister [of Health]." ${ }^{18}$ In Ethiopia, the director shall, among other mandates, “... prepare a workplan and submit a budget to the Ministry of Health (d) expend resources according to the Ministry approved budget." 14

\section{Accountability and Reporting}

Domain IV, "The legal instrument establishes oversight or advisory boards," and Domain V, "The legal instrument establishes accountability and reporting mechanisms," include attributes related to oversight and accountability for NPHIs (Tables 4 and 5). Analysis of NPHI laws shows that all 5 countries have legal provisions establishing NPHI oversight or advisory boards. Four countries (Guinea-Bissau, Liberia, Mozambique, and Nigeria) have laws establishing a board of directors, further articulating a purpose or role for the board and designating oversight functions. For example, in both Guinea-Bissau and Liberia, the board of directors has oversight authority to approve or authorize budgets. ${ }^{16,17}$

Laws for Mozambique, Ethiopia, Guinea-Bissau, Liberia, and Nigeria codify relationships between the NPHI and the ministry of health or other government entities under Domain I. The reporting mechanisms reviewed under Domain V lay out additional requirements for accountability and reporting under the law. While all 5 countries require annual reporting, they vary on the content required to be reported and the recipient of the report. For example, in Liberia, the "Director General shall submit quarterly and annually a report consisting of financial and programmatic information to the Board for onward submission to the President and Legislature." 17 In Liberia, the minister may request the director to submit reports "from time to time on specific issues, programs, or periods." 17 By comparison, the director in Ethiopia must "prepare and submit to the Ministry [of Health] the annual work program and budget of the institute and ... (f) prepare and submit to the Ministry [of Health] the performance and financial reports of the Institute." ${ }^{14}$ While only Ethiopia and Liberia require reporting of significant research findings, 4 countries (Liberia, Ethiopia, Guinea-Bissau, and Nigeria) require reporting on financial expenditures. 
Table 2. Legal Coding for Domain II: The Legal Instrument Describes the Core Public Health Functions of the NPHI

\begin{tabular}{|c|c|c|c|c|c|}
\hline $\begin{array}{l}\text { Domain II: The legal instrument describes the public health } \\
\text { functions of the NPHI }\end{array}$ & Ethiopia & $\begin{array}{l}\text { Guinea- } \\
\text { Bissau }\end{array}$ & Liberia & Mozambique & Nigeria \\
\hline \multicolumn{6}{|l|}{ The legal instrument ... } \\
\hline $2.1 \ldots$ designates administrative roles and functions. & $\bullet$ & $\bullet$ & $\bullet$ & $\bullet$ & $\bullet$ \\
\hline $\begin{array}{l}2.1 .1 \ldots \text { includes authority to manage funds or distribute } \\
\text { funds to others. }\end{array}$ & $\bullet$ & $\bullet$ & $\bullet$ & $\bullet$ & $\bullet$ \\
\hline $\begin{array}{l}2.1 .2 \ldots \text { grants rule-making or regulatory authority to the } \\
\text { NPHI. }\end{array}$ & & & & & $\bullet$ \\
\hline $2.2 \ldots$ designates roles and functions for laboratory systems. & $\bullet$ & $\bullet$ & $\bullet$ & $\bullet$ & $\bullet$ \\
\hline $\begin{array}{l}2.2 .1 \ldots \text { establishes a public health laboratory or laboratory } \\
\text { network. }\end{array}$ & & $\bullet$ & & $\bullet$ & $\bullet$ \\
\hline $\begin{array}{l}2.2 .1 .1 \ldots \text { describes diagnostic test capacity at national, } \\
\text { regional, or district levels. }\end{array}$ & & $\bullet$ & & & \\
\hline 2.2.1.2 ... describes collection of laboratory data. & & & & $\bullet$ & \\
\hline \multicolumn{6}{|l|}{ 2.2.1.2.1 ... includes data-sharing requirements. } \\
\hline 2.2.1.3 ... allows for specimen collection. & & & $\bullet$ & & $\bullet$ \\
\hline $\begin{array}{l}\text { 2.2.1.3.1 } \ldots \text { includes provisions for regulation of } \\
\text { specimen collection. }\end{array}$ & & & & & $\bullet$ \\
\hline $\begin{array}{l}2.2 \cdot 1 \cdot 3.2 \ldots \text { includes provisions for regulation of } \\
\text { specimen transport. }\end{array}$ & & & & & $\bullet$ \\
\hline \multicolumn{6}{|l|}{$\begin{array}{l}\text { 2.2.1.3.3 } \ldots \text { includes provisions for regulation of } \\
\text { specimen storage. }\end{array}$} \\
\hline $2.3 \ldots$ designates roles and functions for surveillance systems. & $\bullet$ & $\bullet$ & $\bullet$ & - & $\bullet$ \\
\hline $\begin{array}{l}2.3 .1 \ldots \text { permits activities for the prevention and control of } \\
\text { infectious diseases. }\end{array}$ & $\bullet$ & $\bullet$ & $\bullet$ & $\bullet$ & $\bullet$ \\
\hline 2.3.1.1 ... permits data collection on infectious diseases. & $\bullet$ & & $\bullet$ & $\bullet$ & $\bullet$ \\
\hline $\begin{array}{l}2.3 .1 .2 \ldots \text { includes provisions for data privacy and } \\
\text { security. }\end{array}$ & & & $\bullet$ & & \\
\hline $\begin{array}{l}\text { 2.3.1.3 } \ldots \text { includes diagnostic capacity for detection and } \\
\text { identification of infectious diseases. }\end{array}$ & $\bullet$ & & $\bullet$ & & $\bullet$ \\
\hline $\begin{array}{l}\text { 2.3.1.4 ... allows for systematic, ongoing collection of } \\
\text { data for public health purposes. }\end{array}$ & $\bullet$ & & $\bullet$ & $\bullet$ & $\bullet$ \\
\hline \multicolumn{6}{|l|}{$\begin{array}{l}2.3 .1 .5 \ldots \text { includes provisions for mandatory reporting } \\
\text { within the country. }\end{array}$} \\
\hline 2.3.1.6 ... includes provisions for international reporting. & $\bullet$ & & & & $\bullet$ \\
\hline $\begin{array}{l}\text { 2.3.2 } \ldots \text { permits activities for prevention and control of } \\
\text { noncommunicable diseases. }\end{array}$ & $\bullet$ & $\bullet$ & $\bullet$ & $\bullet$ & $\bullet$ \\
\hline $\begin{array}{l}\text { 2.3.2.1 ... permits data collection on noncommunicable } \\
\text { diseases. }\end{array}$ & $\bullet$ & & $\bullet$ & $\bullet$ & $\bullet$ \\
\hline $\begin{array}{l}\text { 2.3.2.2 } \ldots \text { includes diagnostic capacity for detection and } \\
\text { identification of noncommunicable diseases. }\end{array}$ & & & $\bullet$ & & $\bullet$ \\
\hline $\begin{array}{l}\text { 2.3.2.3 ... allows for systematic, ongoing collection of } \\
\text { data for public health purposes. }\end{array}$ & $\bullet$ & • & $\bullet$ & $\bullet$ & $\bullet$ \\
\hline \multicolumn{6}{|l|}{$\begin{array}{l}\text { 2.3.2.4 } \ldots \text { includes provisions for the development of } \\
\text { health indicators. }\end{array}$} \\
\hline $\begin{array}{l}2.3 .2 .5 \ldots \text { includes provisions for reporting within the } \\
\text { country. }\end{array}$ & & & & & \\
\hline
\end{tabular}

(continued) 
Table 2. (Continued)

\begin{tabular}{|c|c|c|c|c|c|}
\hline $\begin{array}{l}\text { Domain II: The legal instrument describes the public health } \\
\text { functions of the NPHI }\end{array}$ & Ethiopia & $\begin{array}{l}\text { Guinea- } \\
\text { Bissau }\end{array}$ & Liberia & Mozambique & Nigeria \\
\hline $2.4 \ldots$ permits activities for epidemiologic investigation. & $\bullet$ & & - & - & $\bullet$ \\
\hline $\begin{array}{l}2.5 \ldots \text { permits activities for a public health emergency } \\
\text { response function within the NPHI. }\end{array}$ & $\bullet$ & & $\bullet$ & & $\bullet$ \\
\hline $2.5 .1 \ldots$ allows for emergency preparedness activities. & $\bullet$ & & $\bullet$ & & $\bullet$ \\
\hline $\begin{array}{l}2.5 .1 .1 \ldots \text { authorizes the development of public health } \\
\text { response plans and/or procedures. }\end{array}$ & $\bullet$ & & & & \\
\hline \multicolumn{6}{|l|}{$\begin{array}{l}2.5 .1 .2 \ldots \text { authorizes establishment of an incident com- } \\
\text { mand structure for public health emergencies. }\end{array}$} \\
\hline $\begin{array}{l}2.5 .1 .3 \ldots \text { authorizes public health emergency response } \\
\text { training. }\end{array}$ & $\bullet$ & & $\bullet$ & & \\
\hline $\begin{array}{l}2.5 .2 \ldots \text { makes provisions for public health surveillance } \\
\text { during times of emergency. }\end{array}$ & $\bullet$ & & $\bullet$ & & \\
\hline $\begin{array}{l}2.5 .3 \ldots \text { provides for coordination and communication } \\
\text { among sectors during public health emergencies. }\end{array}$ & $\bullet$ & & & & $\bullet$ \\
\hline $\begin{array}{l}\text { 2.5.3.1 ... includes provisions related to multisectoral } \\
\text { communication. }\end{array}$ & $\bullet$ & & & & $\bullet$ \\
\hline $\begin{array}{l}\text { 2.5.3.2 } \ldots \text { makes provision for designation of a focal } \\
\text { point for communication. }\end{array}$ & $\bullet$ & & & & $\bullet$ \\
\hline $\begin{array}{l}2.5 .4 \ldots \text { describes certain powers related to public health } \\
\text { emergency response. }\end{array}$ & & & $\bullet$ & & $\bullet$ \\
\hline \multicolumn{6}{|l|}{$\begin{array}{l}2.5 .4 .1 \ldots \text { makes provision for the declaration of a public } \\
\text { health emergency. }\end{array}$} \\
\hline \multicolumn{6}{|l|}{$\begin{array}{l}\text { 2.5.4.2 ... establishes procedures to enable quarantine } \\
\text { during emergencies. }\end{array}$} \\
\hline \multicolumn{6}{|l|}{$\begin{array}{l}\text { 2.5.4.3 ... establishes procedures to enable isolation } \\
\text { during emergencies. }\end{array}$} \\
\hline $\begin{array}{l}2.6 \ldots \text { designates roles and functions for disease prevention } \\
\text { and health promotion. }\end{array}$ & $\bullet$ & $\bullet$ & $\bullet$ & $\bullet$ & \\
\hline $\begin{array}{l}2.6 .1 \ldots \text { authorizes behavioral health and communication } \\
\text { activities. }\end{array}$ & & $\bullet$ & $\bullet$ & $\bullet$ & \\
\hline $\begin{array}{l}2.6 .2 \ldots \text { requires policy development for health promotion } \\
\text { and for disease prevention and control. }\end{array}$ & & $\bullet$ & $\bullet$ & $\bullet$ & \\
\hline 2.6.3 ... specifies creation of a health promotion function. & & & & $\bullet$ & \\
\hline $\begin{array}{l}2.7 \ldots \text { designates the roles of and functions for workforce } \\
\text { development. }\end{array}$ & $\bullet$ & $\bullet$ & $\bullet$ & $\bullet$ & $\bullet$ \\
\hline \multicolumn{6}{|l|}{$\begin{array}{l}2.7 .1 \ldots \text { requires identification of public health workforce } \\
\text { needs. }\end{array}$} \\
\hline $\begin{array}{l}2.7 .2 \ldots \text { authorizes public health workforce training } \\
\text { activities. }\end{array}$ & $\bullet$ & $\bullet$ & & $\bullet$ & \\
\hline $\begin{array}{l}2.7 .3 \ldots \text { describes other workforce capacity-building } \\
\text { activities. }\end{array}$ & $\bullet$ & & & & \\
\hline $\begin{array}{l}2.8 \ldots \text { establishes roles and functions for public health research } \\
\text { and development. }\end{array}$ & • & • & • & • & • \\
\hline 2.8.1 ... authorizes public health research activities. & $\bullet$ & $\bullet$ & $\bullet$ & $\bullet$ & $\bullet$ \\
\hline $\begin{array}{l}2.8 .2 \ldots \text { authorizes public health monitoring and evalua- } \\
\text { tion activities. }\end{array}$ & & $\bullet$ & & - & $\bullet$ \\
\hline
\end{tabular}


Table 3. Legal Coding for Domain III: The Legal Instrument Describes the Leadership Structure for the NPHI

\begin{tabular}{|c|c|c|c|c|c|}
\hline $\begin{array}{l}\text { Domain III: The legal instrument establishes the leadership structure } \\
\text { of the NPHI }\end{array}$ & Ethiopia & $\begin{array}{l}\text { Guinea- } \\
\text { Bissau }\end{array}$ & Liberia & Mozambique & Nigeria \\
\hline \multicolumn{6}{|l|}{ The legal instrument.. } \\
\hline $3.1 \ldots$ establishes the role of NPHI director. & $\bullet$ & $\bullet$ & $\bullet$ & $\bullet$ & $\bullet$ \\
\hline $\begin{array}{l}3.1 .1 \ldots \text { describes processes for appointment, resignation, or removal } \\
\text { or addresses tenure. }\end{array}$ & $\bullet$ & $\bullet$ & $\bullet$ & $\bullet$ & $\bullet$ \\
\hline 3.1.2 $\ldots$ describes the role, duty, and authority of the director. & $\bullet$ & $\bullet$ & $\bullet$ & $\bullet$ & $\bullet$ \\
\hline 3.1.2.1... describes limitations on authority of the director. & $\bullet$ & & & $\bullet$ & \\
\hline $\begin{array}{l}3.1 .3 \ldots \text { establishes professional qualifications or other competencies } \\
\text { for the NPHI director. }\end{array}$ & $\bullet$ & $\bullet$ & $\bullet$ & & $\bullet$ \\
\hline $3.2 \ldots$ establishes the role of NPHI deputy director. & $\bullet$ & & $\bullet$ & $\bullet$ & \\
\hline $\begin{array}{l}3.2 .1 \ldots \text { describes processes for appointment, resignation, or removal } \\
\text { or addresses tenure. }\end{array}$ & & & $\bullet$ & $\bullet$ & \\
\hline $3.2 .2 \ldots$ describes the role, duty, and authority of the deputy director. & & & $\bullet$ & $\bullet$ & \\
\hline \multicolumn{6}{|l|}{ 3.2.2.1 ... describes limitations on authority. } \\
\hline $\begin{array}{l}3.2 .3 \ldots \text { establishes professional qualifications or other competencies } \\
\text { for the NPHI deputy director. }\end{array}$ & & & $\bullet$ & & \\
\hline $\begin{array}{l}3.3 \text {... establishes the role of technical or administrative department } \\
\text { leads. }\end{array}$ & & & & $\bullet$ & $\bullet$ \\
\hline $\begin{array}{l}\text { 3.3.1 ... establishes the position of director for each of the depart- } \\
\text { ments of the NPHI. }\end{array}$ & & & & & $\bullet$ \\
\hline \multicolumn{6}{|l|}{$\begin{array}{l}\text { 3.3.1.1 ... address processes for appointment, resignation, or } \\
\text { removal or tenure. }\end{array}$} \\
\hline \multicolumn{6}{|l|}{ 3.3.1.2 $\ldots$ describes the role, duty, and authority of the director. } \\
\hline \multicolumn{6}{|l|}{ 3.3.1.2.1 ... describes limitations on authority of the director. } \\
\hline $\begin{array}{l}\text { 3.3.1.3 ... establishes professional qualifications or other } \\
\text { competencies. }\end{array}$ & & & & & \\
\hline
\end{tabular}

\section{Discussion}

With the increased attention to the key role NPHIs can play in global health security and the emphasis on NPHIs by the Africa CDC, ${ }^{23}$ there is a need for tools that help establish or strengthen NPHIs. The NPHI Legal Framework and the approach to analysis presented here are such tools. By laying out a detailed menu of considerations, the NPHI Legal Framework provides a basis for countries to establish NPHI laws and for other countries to identify gaps and opportunities in the law. ${ }^{12}$ Because of the role NPHIs play in the overall strengthening of the public health systems, description and designation of functions helps establish the range of allowable competencies to help achieve NPHI goals and can make clearer who has the authority to act during public health emergencies. In addition, the law can articulate the legal character of the organization and how it fits into the overall government structure and can establish certain technical requirements for those that lead NPHIs.

Just as NPHIs vary widely in structure, public health functions, and attributes, the mechanisms used to establish NPHIs and the content of their laws vary. ${ }^{12}$ For example, while Mozambique, Liberia, Guinea-Bissau, Ethiopia, and Nigeria establish parastatal NPHI structures, this is not the case for all NPHIs. Even among the countries reviewed that chose to establish parastatal structures, the review showed significant diversity related to autonomy and the NPHIs' relationship to the ministry of health. For example, some countries have chosen to maintain significant institutional ties to the ministry of health, while others do not directly require such direct institutional linkages. ${ }^{18,19}$ In Mozambique, the NPHI is under the direct tutelage of the ministry of health, and the minister maintains the authority to approve and authorize INS rules, annual reports, and activity plans. ${ }^{18,19}$ On the other hand, Liberia only requires the NPHI to maintain sectoral reporting accountability and sharing of scientific information reports with the ministry of health. ${ }^{17}$

Because of the role NPHIs play in the overall strengthening of public health systems, description and designation of functions in the law help to establish public health roles for the NPHI that have a high priority. Therefore, the role of a legal instrument is largely to clarify and formally establish these roles, responsibilities, and relationships. Many 
Table 4. Legal Coding for Domain IV: The Legal Instrument Establishes NPHI Oversight or Advisory Boards

\begin{tabular}{|c|c|c|c|c|c|}
\hline $\begin{array}{l}\text { Domain IV: The legal instrument establishes NPHI oversight } \\
\text { or advisory boards }\end{array}$ & Ethiopia & $\begin{array}{c}\text { Guinea- } \\
\text { Bissau }\end{array}$ & Liberia & Mozambique & Nigeria \\
\hline \multicolumn{6}{|l|}{ The legal instrument ... } \\
\hline 4.1 ... establishes a board of directors. & & $\bullet$ & $\bullet$ & $\bullet$ & • \\
\hline 4.1.1 ... articulates a role or purpose for the board. & & $\bullet$ & $\bullet$ & $\bullet$ & $\bullet$ \\
\hline 4.1.1.1 ... designates oversight functions. & & $\bullet$ & - & $\bullet$ & $\bullet$ \\
\hline 4.1.1.1.1 ... provides the board with authority to approve budgets. & & $\bullet$ & - & $\bullet$ & $\bullet$ \\
\hline $\begin{array}{l}4.1 .1 .1 .2 \ldots \text { provides powers to the board related to NPHI leadership } \\
\text { positions. }\end{array}$ & & $\bullet$ & $\bullet$ & $\bullet$ & $\bullet$ \\
\hline $4.1 .2 \ldots$ sets guidelines for the composition of boards. & & $\bullet$ & $\bullet$ & & $\bullet$ \\
\hline 4.1.2.1 ... identifies sectors for mandated representation on the board. & & $\bullet$ & $\bullet$ & & $\bullet$ \\
\hline $\begin{array}{l}\text { 4.1.2.2 Representation from various ministries, eg, MOA or MOE, is } \\
\text { mandated. }\end{array}$ & & - & - & & - \\
\hline \multicolumn{6}{|l|}{ 4.1.2.3 Representation from law enforcement is mandated. } \\
\hline 4.1.2.4 Representation from the academic sector is mandated. & & $\bullet$ & $\bullet$ & & \\
\hline $\begin{array}{l}\text { 4.1.2.5 Representation from the private sector and/or civil society is } \\
\text { mandated. }\end{array}$ & & & & & $\bullet$ \\
\hline 4.1.3 ... stipulates how the board's membership is determined. & & $\bullet$ & $\bullet$ & & $\bullet$ \\
\hline $\begin{array}{l}4.1 .3 .1 \ldots \text { describes how members are selected or designates authority to } \\
\text { an entity. }\end{array}$ & & $\bullet$ & $\bullet$ & & $\bullet$ \\
\hline 4.1.3.2 ... sets board member tenure. & & $\bullet$ & $\bullet$ & & $\bullet$ \\
\hline $\begin{array}{l}4.1 .4 \ldots \text { establishes parameters for the board operation and conduct of } \\
\text { business. }\end{array}$ & & $\bullet$ & $\bullet$ & & \\
\hline 4.1.4.1 ... establishes board convening periodicity. & & & $\bullet$ & & \\
\hline $\begin{array}{l}4.1 .4 .2 \ldots \text { creates requirements re: decision making, recording keeping, } \\
\text { or public engagement. }\end{array}$ & & $\bullet$ & $\bullet$ & & \\
\hline $\begin{array}{l}4.2 \text {... enables other boards or bodies (eg, IRBs, scientific advisory boards, } \\
\text { etc). }\end{array}$ & $\bullet$ & - & $\bullet$ & $\bullet$ & $\bullet$ \\
\hline 4.2.1 ... specifies the function of other boards. & $\bullet$ & $\bullet$ & $\bullet$ & $\bullet$ & $\bullet$ \\
\hline 4.2.1.1 ...grants oversight functions. & & $\bullet$ & & $\bullet$ & \\
\hline 4.2.1.2 ...grants advisory functions. & $\bullet$ & $\bullet$ & $\bullet$ & $\bullet$ & $\bullet$ \\
\hline $\begin{array}{l}\text { 4.2.2 } \ldots \text { includes makeup of the board and/or the selection and tenure of } \\
\text { its members. }\end{array}$ & • & $\bullet$ & & & $\bullet$ \\
\hline $\begin{array}{l}4.2 .3 \ldots \text { makes provisions related to the conduct of business of other boards } \\
\text { or bodies. }\end{array}$ & $\bullet$ & & & & \\
\hline
\end{tabular}

NPHIs play a critical role in supporting key public health functions such as surveillance, outbreak preparedness and response, laboratory quality assurance, and public health research, among other functions. Given the variability in structure for NPHIs, the designation of specific functions can also serve as a blueprint for mapping which activities fall under the purview of the NPHI and what authorities reside elsewhere. This is particularly important for ensuring multisectoral and cross-sectoral collaboration in order to avoid duplication of efforts or any potential conflict of law. For example, as seen in Domain II, depending on the
NPHI's role, surveillance and data-sharing functions may need to specify the collaborative relationships with sister institutes, government agencies, international organizations, universities, nongovernmental organizations, and professional societies. Other countries may use the designated functions to specify special authorities, such as authorizing the NPHI to engage in emergency preparedness activities, to designate and clarify what specific responsibilities rest with the NPHI for emergency operations. In particular, as countries develop new or enhance existing NPHI structures, the NPHI legal framework can serve as a 
Table 5. Legal Coding for Domain V: The Legal Instrument Establishes Accountability and Reporting Mechanisms

\begin{tabular}{|c|c|c|c|c|c|}
\hline $\begin{array}{l}\text { Domain V: The legal instrument establishes accountability } \\
\text { and reporting mechanisms }\end{array}$ & Ethiopia & Guinea-Bissau & Liberia & Mozambique & Nigeria \\
\hline \multicolumn{6}{|l|}{ The legal instrument ... } \\
\hline 5.1 ... establishes reporting mechanisms. & $\bullet$ & $\bullet$ & $\bullet$ & $\bullet$ & $\bullet$ \\
\hline $5.1 .1 \ldots$ requires reporting on a regular recurring basis. & $\bullet$ & $\bullet$ & $\bullet$ & $\bullet$ & $\bullet$ \\
\hline $5.1 .1 .1 \ldots$ requires annual reporting. & $\bullet$ & $\bullet$ & $\bullet$ & $\bullet$ & $\bullet$ \\
\hline $5.1 .2 \ldots$ specifies content that is to be reported. & $\bullet$ & $\bullet$ & $\bullet$ & $\bullet$ & $\bullet$ \\
\hline $\begin{array}{l}5.1 .2 .1 \ldots \text { requires regular updates from departments } \\
\text { or from programs. }\end{array}$ & & & $\bullet$ & & \\
\hline 5.1.2.2 $\ldots$ requires reporting of financial expenditures. & $\bullet$ & $\bullet$ & $\bullet$ & & $\bullet$ \\
\hline 5.1.2.3 $\ldots$ requires reporting of significant research findings. & $\bullet$ & & $\bullet$ & & \\
\hline \multicolumn{6}{|l|}{ 5.1.2.4 ... mandates reporting of population-level health data. } \\
\hline $\begin{array}{l}5.1 .2 .5 \ldots \text { mandates development of and reporting } \\
\text { on health indicators. }\end{array}$ & & & & & \\
\hline
\end{tabular}

valuable tool for addressing potential conflict of authorities that could be faced as new entities are developed and expanded.

Lastly, strong NPHI authorities can be used to help catalyze country activities toward achieving greater IHR compliance and can be used to ensure an increased coordination and cooperation both nationally and internationally toward prevention and control of disease. ${ }^{11}$ Given the role of law in the overall capacity development process, including as measured by the JEE, countries may consider review of NPHI legal authorities to determine if gaps exist and whether addressing legal gaps will demonstrate capacity development progress as measured through the JEE. ${ }^{3,5}$ Moreover, the JEE highlights that, even if national legal systems do not require revised legislation to implement health system changes, revisions may still be a "more efficient, effective or beneficial manner" for implementation of health system interventions. ${ }^{3}$

\section{Conclusion}

A strong legislative and regulatory framework can assist countries in building support for further public health capacity development, including establishment of sustainable norms to support IHR core capacities. ${ }^{24}$ The JEE's national legislation, policy, and financing capacity area specifically underscores the role of law and policy by calling on nations to support and enable IHR implementation with a legal framework. ${ }^{2}$ Given the increased effort by countries to meet these core capacities, the legal framework and menu of considerations for NPHIs provides a standardized tool to review existing authorities. As additional countries strive to develop new NPHIs or strengthen existing ones, the legal framework and menu of considerations provides stakeholders with a resource to enhance activities to clarify, establish, or enhance the legal foundation for the NPHI. ${ }^{12}$ The legal framework and menu of considerations can provide stakeholders with a structured approach to conducting legal mapping of existing laws to identify where additional laws could help strengthen the public health infrastructure and support the continuity of the NPHI structure over time. ${ }^{12}$ Given the variability in legal approaches used to establish and enable NPHIs, the legal framework and menu of considerations provides a roadmap to review and identify areas of opportunity to strengthen NPHI laws, while also providing flexibility for country-specific determinations.

\section{ACKNOWledgments}

The authors would like to acknowledge the collaboration, support, and contributions provided by ministries of health and other key partners from the Africa Centres for Disease Control and Prevention, Emory University School of Law, Guinea Bissau National Institute of Public Health, the International Association of National Public Health Institutes, Mozambique Instituto Nacional de Saude, National Public Health Institute of Liberia, Nigeria Centre for Disease Control, Public Health England, South Africa National Institute of Communicable Diseases, and the US Centers for Disease Control and Prevention on the development of the NPHI framework and subsequent legal framework tools.

\section{REFERENCES}

1. World Health Organization. International Health Regulations (2005). 2d ed. Geneva: WHO; 2008. https://www.who.int/ ihr/9789241596664/en/. Accessed July 17, 2019. 
2. Centers for Disease Control and Prevention. Global Health Security Agenda: Action Packages. Updated January 21, 2016. http://www.cdc.gov/globalhealth/security/actionpackages/ default.htm. Accessed July 17, 2019.

3. World Health Organization. Joint External Evaluation Tool: International Health Regulations (2005). Geneva: WHO; 2016. http://apps.who.int/iris/bitstream/10665/204368/1/ 9789241510172_eng.pdf?ua=1. Accessed August 4, 2019.

4. Morhard R, Katz R. Legal and regulatory capacity to support the Global Health Security Agenda. Biosecur Bioterror 2014; 12(5):254-262.

5. Menon AN, Rosenfeld E, Brush CA. Law and the JEE: lessons for IHR implementation. Health Secur 2018;16(Suppl 1):S11S17.

6. Barzilay EJ, Vandi H, Binder S, et al. Use of the staged developing tool for assessing, planning, and measuring progress in the development of national public health institutes. Health Secur 2018;16(Suppl 1):S18-S24.

7. Koplan JP, Puska P, Jousilahti P, et al. Improving the world's health through national public health institutes. Bull World Health Organ 2005;83(2):154-157.

8. International Association of National Public Health Institutes. FAQs. http://www.ianphi.org/whoweare/faqs.html\#q2. Accessed July 17, 2019.

9. International Association of National Public Health Institutes. Framework for the Creation and Development of $\mathrm{Na}$ tional Public Health Institutes. Atlanta: IANHPI; 2007. http:// ianphi.org/_includes/documents/frameworkfornphi.pdf. Accessed July 17, 2019.

10. Frieden TR, Koplan JP. Stronger national public health institutes for global health. Lancet 2010;376(9754):17211722 .

11. Rodier G, Greenspan AL, Hughes JM, Heymann DL. Global public health security. Emerg Infect Dis 2007;13(10): 1447-1452.

12. International Association of National Public Health Institutes. Providing a Legal Framework for a National Public Health Institute (NPHI). Africa Union; Africa Centres for Disease Control; undated. http://www.ianphi.org/_includes/ documents/legalframeworkenglish_version8. Accessed July 17, 2019.

13. Gostin LO, Wiley LF. Public Health Law: Power, Duty, Restraint. 3d ed. Oakland: University of California Press; 2016.

14. Federal Democratic Republic of Ethiopia Council of Ministers. Ethiopian Public Health Institute Establishment Council of Ministers Regulation No. 301/2013. 2014. http://www.ianphi.org/_includes/documents/Ethiopia_regula tion1.pdf. Accessed July 18, 2019.
15. Kebede A. NPHI case study: profile of creation and growth. Ethiopia Public Health Institute (EPHI). January 2013. http://www.ianphi.org/_includes/documents/EPHIcasestudy .pdf. Accessed on August 4, 2019.

16. Cabinet Council of Guinea Bissau. National Institute of Public Health (INASA). 2010. http://www.ianphi.org/_includes/ documents/INASA1.pdf. Accessed on August 4, 2019.

17. National Assembly of Liberia. National Public Health Institute of Liberia Act. 2016. http://ianphi.org/resources/ toolkit/nphilegislation.html. Accessed on August 4, 2019.

18. Council of Ministers of Mozambique. Decree No. 57/2017: Nature, Attributions, and Competencies of the National Institute of Health for Coordination and Management of Health Research. 2017. http://ianphi.org/_includes/images/ uploads/inslogo. Accessed on August 4, 2019.

19. Council of Ministers of Mozambique. Resolucao 17/2018 Estatuto Organico do INS. 2018. http://www.misau.gov.mz/ index.php/resolucoes. Accessed on August 4, 2019.

20. National Assembly of Nigeria. Nigeria Centre for Disease Control and Prevention (Establishment) Act. 2018. http:// www.ianphi.org/_includes/documents/NCDC\%20Official\%20 Gazette.pdf. Accessed on August 4, 2019.

21. Njidda AM, Oyebanji O, Obasanya J, et al. The Nigeria Centre for Disease Control. BMJ Glob Health 2018;3(2):e000712.

22. Burris S, Ashe M, Levin D, Penn M, Larkin M. A transdisciplinary approach to public health law: the emerging practice of legal epidemiology. Annu Rev Public Health 2016; 37:135-148.

23. Africa Centres for Disease Control and Prevention. Communique on strengthening and establishing national public health institutes as part of the Africa Centres for Disease Control and Prevention. http://africacdc.org/resources/continentalcommitments/continental-commitments/communique-onstrengthening-and-establishing-national-public-health-institutesas-part-of-a-network-of-the-africa-centres-for-disease-controland-prevention/detail. Accessed August 4, 2019.

24. Attal-Juncqua A, Standley CJ, Tordjmann A, Burci GL, Katz R. Legislative assessments as a tool for strengthening health security capacity: the example of Guinea post-2014 Ebola outbreak. J Glob Health Rep 2019;3:e2019060.

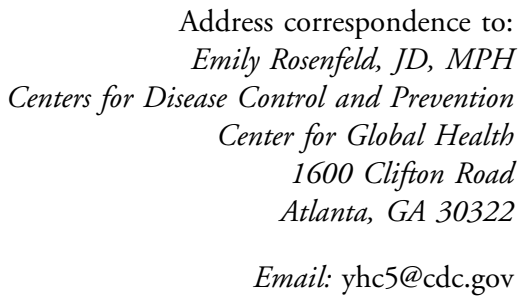

Address correspondence to: ase Control and Prevention 1600 Clifton Road Email: yhc5@cdc.gov 